\title{
Integration of Mechatronic and Automation Technology in Sustainable Farming for Achieving Food Security in Kenya
}

\author{
Geoffrey K. Ontiri and Lilian L. Amuhaya
}

\begin{abstract}
Advanced farming that involves modern technology, especially in large scale, can aid in attaining food security for any given country. In this study, the prospects of automation, mechatronics and the developments for modern farming are explored for sustainable agriculture in Kenya. For the purpose of technological diversification, the use of mechatronics and automation in various smart farming technological systems is presented. It is possible to step up development in realizing food security in Kenya with the use of these modern farming techniques among other similar technologies. The use Artificial Intelligence (AI), Machine Learning (ML), Internet of Things (IOT), Global System for Mobile (GSM) Communications, photovoltaic thermal solar systems, cloud data storage and radio frequency identification (RFID) technologies that are utilized in autonomous tractors, drone farming, livestock monitoring, smart poultry, dairy, irrigation, greenhouse, and farm warehouse systems are discussed. These advances can result in significant increase in production, efficiency, profits, as well as better monitoring, surveillance and tracking in the farm. Finally, the impact of these technologies on agriculture in relation to sustainable food security is explored, where it is demonstrated that mechatronic farm automation integrated with the mobile applications can offer better farm monitoring, increase yields as well as contribute towards better land utilization.
\end{abstract}

Keywords - Farm automation; mechatronics; smart farming; sustainable food security.

\section{INTRODUCTION}

Food is a basic need for human beings and for this reason, there is a global debate and focus concerning the food security to cater for the growing world population. This concern as addressed in various conferences, meetings, and forums, is progressively raising a need for formulation of governing policies for sustainable food production which include the integrated food system approach, economical land utilization, environmental protection and other practices aimed at minimizing hunger [1]. The current trends in food security according to Food and Agriculture Organization (FAO) indicate that an estimated 821 million people globally are underfed [2]. The Global Hunger Index (GHI) report of 2020 indicate that many African countries are experiencing high levels of hunger where Kenya, Nigeria and Mali among others have a serious hunger level as indicated in Fig. 1 [3].

Submitted on January 28, 2022.

Published on February 22, 2022

G. K. Ontiri, Egerton University, Kenya.

(e-mail: geoffreyontiri@gmail.com)

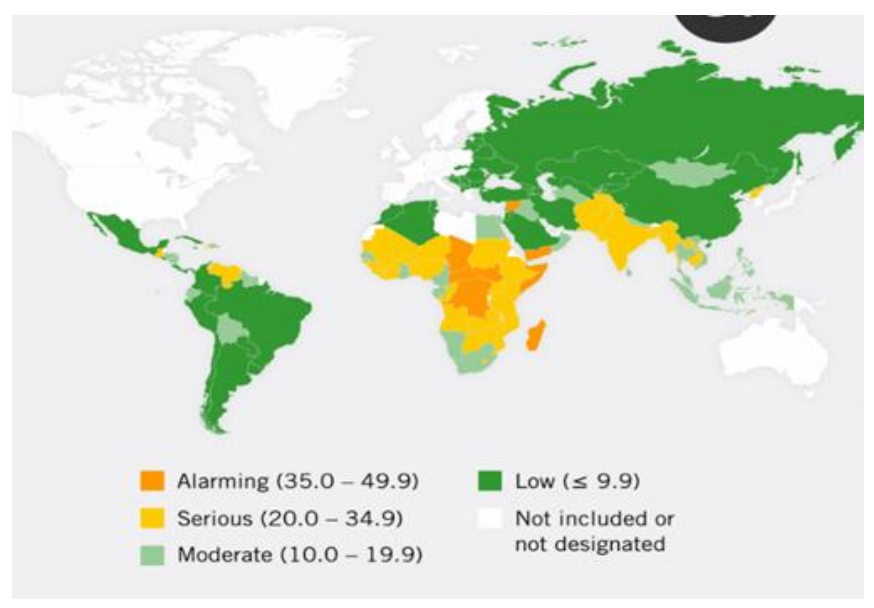

Fig. 1. World global hunger index [3].

According to the 2020 overview of the Global Food Security Index (GFSI) [4], Kenya with a preference of undernourishment of $23 \%$ has challenges in agricultural research and development as well as sufficiency of food supply. Based on the same report, it also has global ranking indicator scores of 78, 102, 75 and 72 for food affordability, availability, quality, and resilience respectively when assessed based on the four pillars of food security. A forecast report [5] by the International Futures (IFs) based on FAOSTAT data has indicated that Kenya will experience a higher consumption than production by almost 20 million metric tons by 2040 as shown in Fig. 2. Therefore, food sustainability is major concern for Kenya like other SubSaharan African countries.

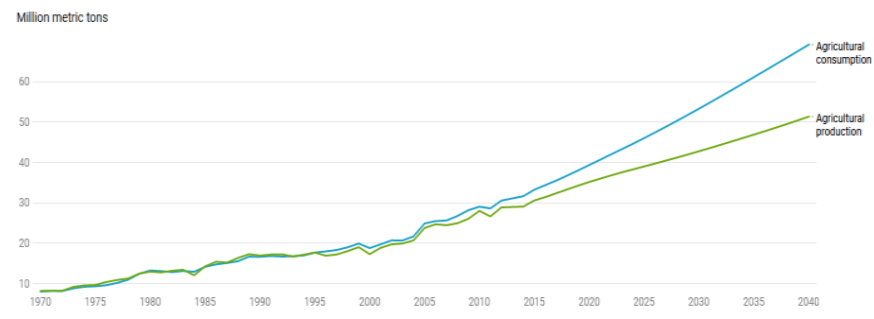

Fig. 2. History and forecast of agricultural production and consumption in Kenya.

\section{FOOD SECURITY IN KENYA}

In an effort to address the looming food supply crisis in the near future in Kenya, food security is one of the four pillars

Lilian L. Amuhaya, Egerton University, Kenya

(e-mail: livuambo@ hotmail.com) 
in the economic blueprint formulated by the current administration of the Kenyan government that was launched on $12^{\text {th }}$ December 2017 and dubbed as the "big four agenda" [6]. This economic strategy seeks to advance economic development and mitigate the existing socio-economic challenges that are affecting the Kenyan citizens. The salient objectives in the food security agenda are (1) $47 \%$ and $50 \%$ reductions of food cost per income and food insecure citizens respectively as well as (2) $48 \%$ growth of the agriculture contribution towards the GDP growth [7]. It is evident that food security has attracted great attention even for the Kenyan government and therefore, modern technology that can provide measures for sustainable farming and improve yields of food production will promote the achievement of food security.

Research by [8] has explored how digital farming technology is influencing the policies in agricultural transformation in developing countries based on a case study of China. Another research [9] has presented how modern farming technologies are influencing the value chain in the agricultural systems. This paper will extend the scope of this subject regarding food security and focus on the specific modern farming automation techniques that can be applied in the agricultural mechanization in Kenya, being a developing country so as to realize her dream of food sustainability.

\section{INTEGRATION OF TECHNOLOGY IN FARMING}

The past manual farming has transformed to digital farming where recent technological advances such as smart sensors, actuating devices, autonomous machines, and novel information technology as well as mechatronic systems are taking control of the farming operations [10]. In order to achieve this agricultural transformation in Kenya, mechatronic and other telecommunication technologies can form a firm foundation for integrating modern farming technology. This technology can be utilized right from preparation, production, harvesting and supply of the farm produce to its consumers. The overall result of this will be high precision farming that has minimal wastage as well as improved productivity.

A combination of mechatronic hardware and automation software has led to development of embedded systems that can be implemented in farming fields in order to improve the production, efficiency and profit margins [10]. These systems have an optimal performance provided by various crossplatform technological, computing and telecommunication components. These supporting cross-platform technologies necessary when integrating digital farming include (1) Internet of Things (IoT) - the interconnection of embedded sensors, computing software and related technologies, (2) Cloud of Things (CoT) - this is an advancement of IoT that integrate IoT and cloud storage, (3) Artificial Intelligence (AI), (4) Machine Learning (ML), (5) Geographic Information Systems (GIS), (6) Global Positioning System (GPS) and (7) Global System for Mobile Communications (GSM).

\section{FARM AUTOMATION}

Farming automation as a result of current advances in technology with the aim of providing food security has attracted extensive focus in every country [11]. Through synchronism of mechatronic and automation technology in embedded systems, autonomous farming systems have been developed that perform farming processed without human intervention. Implementing these technologies can be a breakthrough in farming mechanization leading to precision farming and therefore higher farming productivity that will facilitate achieving of food security in Kenya. These farming technological systems are presented as follows.

\section{A. Autonomous Farm Machinery}

The modern technology has come up with autonomous machinery and equipment that can be utilized in farming with little or no human intervention. These are based on robotic technology and can process real-time data from the farm and then execute corresponding farming processed which include tilling, planting, seeding, weeding, fertilizer application, spraying among others.

An investigation conducted [12] has indicated that implementation of autonomous machinery in farming gives a $24 \%$ higher net returns as compared to farming with the conventional manual machinery. In the realm of automation, smart control implies that the implementation of the embedded system based on modern digital technology can be carried out automatically with little or no human intervention [13].

Some of these revolutionary technological developments autonomous farming machinery for prospective application in digital farming are as outlined:

1) GPS-enabled tractors can be utilized in modern farming in order to achieve a regulated field tilling that produces uniform part-width sections for evenly distributed planting and/or seeding, equally distributed fertilizer application as well as spraying of crops. Further, these tractors have an advanced mechanism which can allow an independent control of engine speed and machine velocity, as shown in Fig. 3 [14] and as a result minimize the fuel consumption [15].

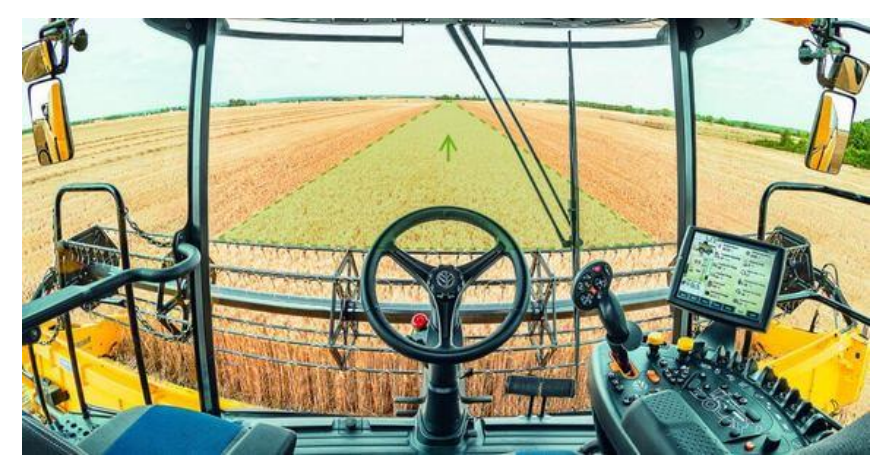

Fig. 3. GPS enabled tractors with independent control

2) GPS based remote controlled robot that combines an embedded autonomous navigation software, as shown in Fig. 4 [16], can be utilized in implementing farm operations that range from crop seeding, crop spraying, self-propelled harvesting and in-field sorting, farm vigilance and theft detection, soil moisture monitoring, bird and animal scaring etc. [11], [16]. Research [17] has established remarkable cost 
saving after the cost-benefit analysis of application of robotics in three cases (that is crop scouting, weeding, and grass cutting) were considered. Therefore, from an economic perspective, agricultural robots can be more profitable when implemented in farming as compared to undertaking the farming operations manually.

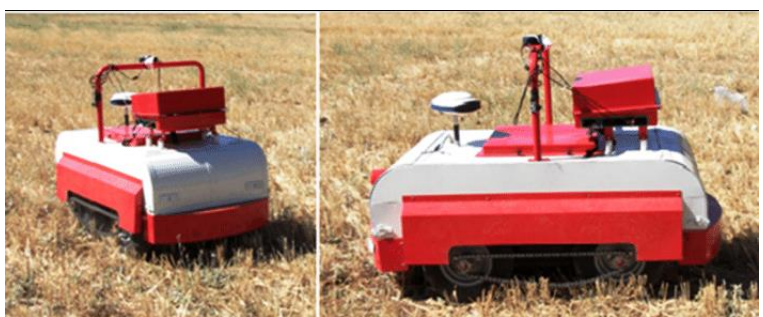

Fig. 4. Remote-controlled and GPS-guided autonomous robot.

3) Auto-steering tractors that combine GIS-based landscape mapping, shown in Fig. 5, can be utilized in various farm activities ranging from tilling to harvesting. These autonomous tractors [18] have a 3D view laser scanner, GPSenabled cameras and other multiple sensor that sense various parameters including the terrain, weather conditions, etc.

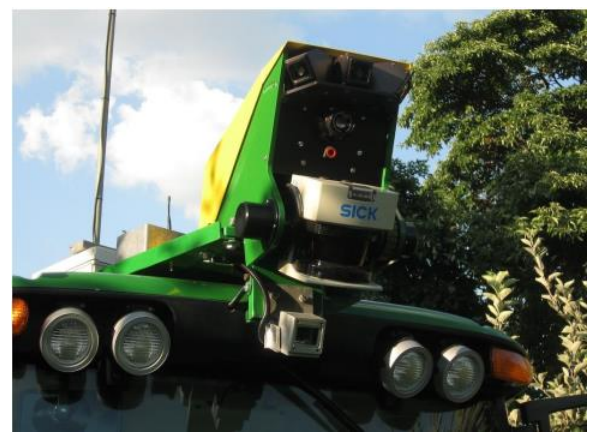

Fig. 5. GPS-based auto-steering tractor.

4) Harvesting machinery like the combiner harvester shown in Fig. 6 that has an integrated camera surveillance system can be utilized in giving the operator an extended span of field vision [15] during farm operation. This improved span of control of the machine provides an enhanced performance of the machinery in the field. Also, an advanced robot harvester with GPS integration and improved accuracy has been developed [19] which can be another good candidate in automating the farm harvesting operations.

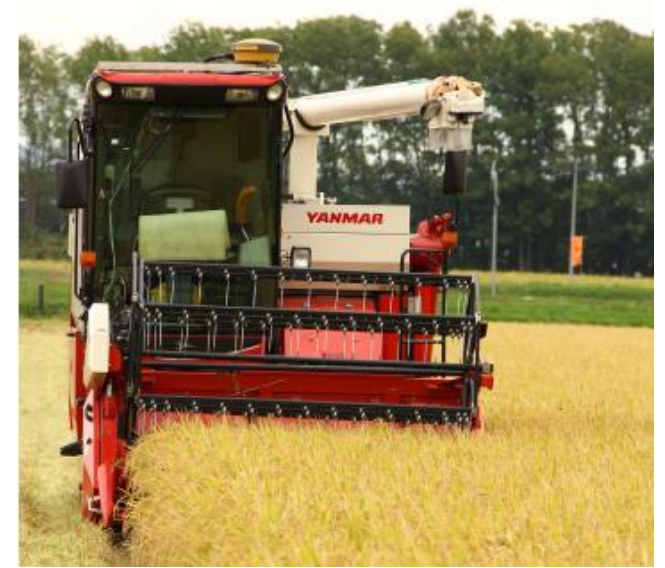

Fig. 6. Combiner harvester with camera s.urveillance.

\section{B. Drone Farming}

Through drone farming, IoT enabled aerial drones can be used to implement aerial imaging that can create crop vegetation indices, field mapping and remote surveillance of the farm. The drones can also integrate IoT sensors in order to provide high precision, real-time farm data collection for parameters such as weather, crop height, water saturation, pest and weed detection etc. which is essential in identifying crop growth stages, crop zoning and classification, monitoring, seeding as well as spraying for example Yamaha's RMAX remote-controlled helicopter [20] used in crop spraying as shown in Fig. 7. The biggest challenge with the implementation of drones in farming is the high initial cost of the drones, however, in terms of economy of scale drone farming greatly contributes to highly productive precision farming by providing improved yielding prediction, field performance analysis, efficiency and accuracy.

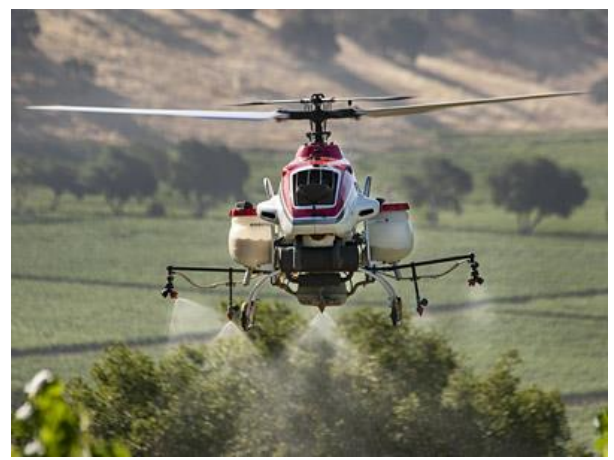

Fig. 7. Yamaha RMAX remote-controlled drone for spraying crops.

\section{Smart Dairy Farm}

A smart dairy farm with automated milking, feed mixing, feed wagons, manure handler as well as livestock monitoring and can be implemented with the following mechatronic systems:

1) Auto-milking machine whose operation and screen output are shown in Fig. 8 [15] used to provide a faster and convenient milking system as well as combining a real-time data collection for milk quality and quantity. The feedback from these milk analytic parameters that are displayed on a screen can be very crucial in monitoring the daily feed to the livestock and also offer an assessment of the general health condition of livestock. The operation of the automatic milking machine is shown in the diagram below:
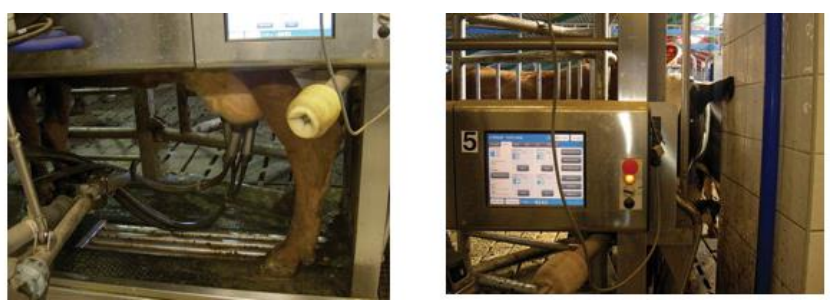

Fig. 8. Representation of smart milking system.

2) IoT-enabled livestock monitoring achieved by installing ear-tag body chip sensors on livestock that collects the body blood pressure, pulse, temperature, and rumination activity among other parameters. Then real-time livestock health condition analysis can be performed based on the ML algorithms to identify possible individual herd infection, 
livestock disease outbreak and recommend possible treatment options. Consequently, the farmer can keep track of the livestock health condition. One of these systems from Zoetis company has been implemented through chip installation by a SMARTBOW technology [21] shown in Fig. 9 which utilize a $96 \%$ accuracy accelerometer-based system [22] to offer precision livestock monitoring.

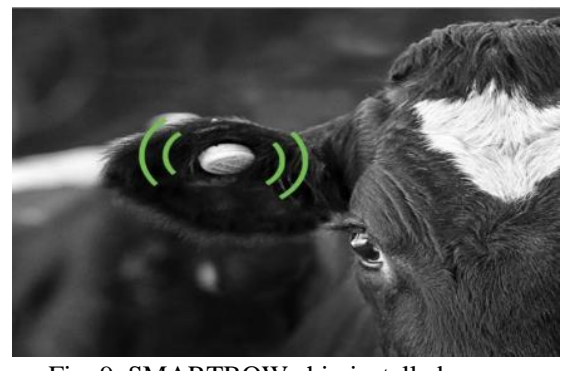

Fig. 9. SMARTBOW chip installed on a cow.

\section{Smart Poultry Farm}

A poultry system [13], [23], [24] can be implemented as shown in fig. 10 with the following automated farm modules that include automated egg collection, automated food, and water supply as well as an automated monitoring system that precisely maintain desirable environmental conditions for the poultry farm.

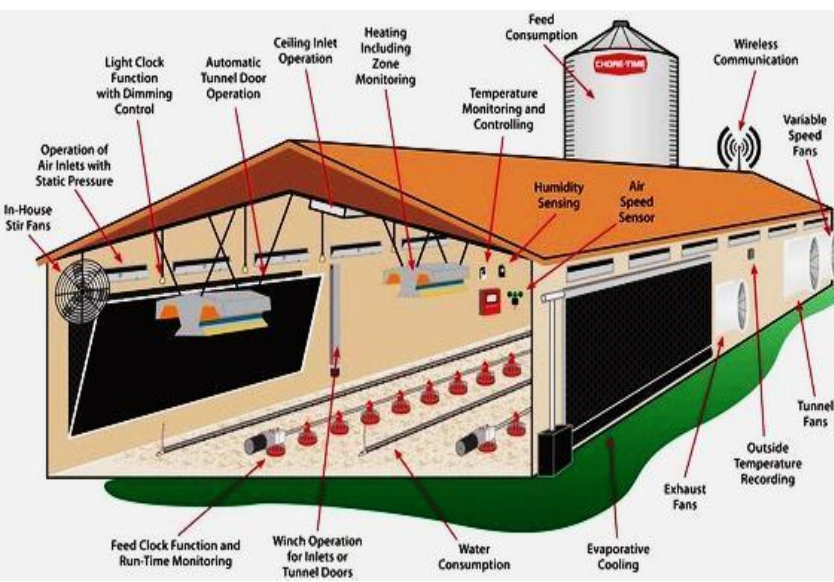

Fig. 10. Smart poultry system [24] integrating IoT sensors, GPRS and GSM modules,

The most crucial technological implementations of the smart poultry farm system include (1) IoT sensors that provide real-time monitoring of the environmental conditions including ammonia gas, humidity, light, temperature etc., (2) GPRS module integrated to provide a convenient remote surveillance and (3) GSM modules incorporated in order to provide the farmer with timely tracking of developments and get intruder alerts where possible.

\section{E. Smart Greenhouses}

The latest greenhouse technology can be integrated through a novel integration of an IoT-based solar-energy enabled smart greenhouse system [25], [26], [24] as shown in Fig. 11 [24].

The automation technologies that the smart greenhouse system integrates for sustainable farming include use of (1) IoT sensors to collect greenhouse data for environmental parameters like humidity, temperature, light, soil moisture, concentration and $\mathrm{pH},(2)$ photovoltaic-thermal (PVT) solar system to generate solar electrical energy needed to operate the electrical system and hence providing economical, renewable and clean energy and (3) cloud computing based on the Wireless Sensor Network (WSN) nodes that offer cloud data storage and therefore enable remote control of greenhouse system

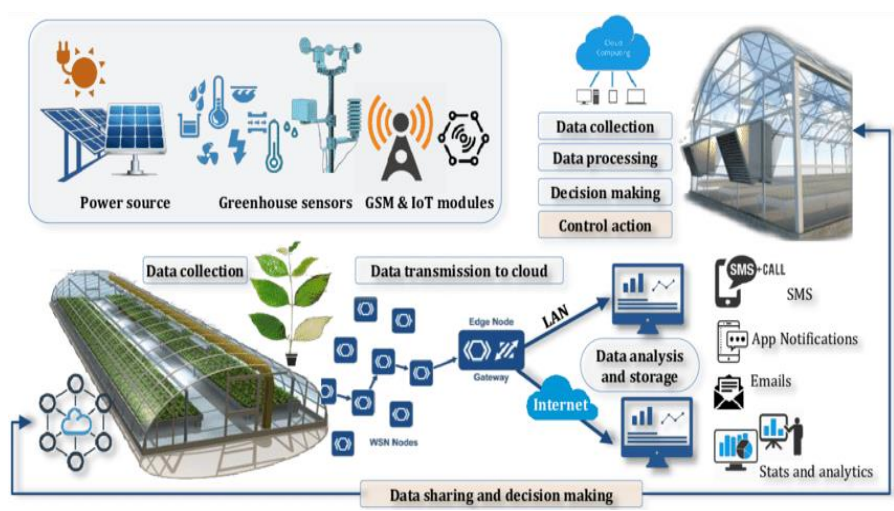

Fig. 11. IoT-based solar-energy enabled smart greenhouse system.

\section{F. Smart Farm Irrigation}

Mechatronic and automation technologies can develop and implement [27]-[29] a modern smart irrigation system that works in real-time based on the field data by combining and adopting the following technologies: (1) IoT-based sensor modules distributed in strategic locations in the farm (i.e. nodes) to collect various parameters including, temperature, humidity, soil moisture and water level and (2) CoT-based thermal imaging as shown in the sample output in Fig. 12 that offer a remote mapping of the field surface temperature as well as analysis of water concentration at various regions and therefore offering a technique that will prioritize on the less watered regions in order to ensure that there is uniformity in water distribution throughout the farming field [30].

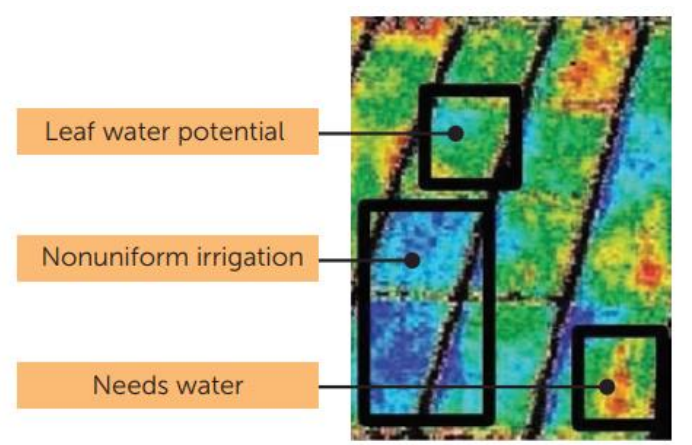

Fig. 12. Output of CoT bases thermal imaging smary irrigation.

Also, (3) ML-based controllers that rely on machine learning algorithms in order to achieve real-time modelling of the irrigation trend are integrated in the smart irrigation system. Micro-controllers such as Arduino-Mega, or single board computer Raspberry Pi, can be economical for smallscale farm applications whereas Programmable Logic Controllers can be ideal for large-scale farm applications. Specially designed actuators can implement the desired irrigation operations by regulating the opening and closing of valves and sprinklers as well as the rate of flow of water.

Further integration of distributed Wireless Sensor Network 
(WSN) that comprises of Wi-Fi modules at each node facilitate the communication between the IoT sensors, controller and the database stored in a cloud-based server in order to be accessed remotely in the field. The smart irrigation system can rely on the sensor modules to collect data from the farm, micro-controllers to process the data and mobile technologies to present the processed information [27].

The automated irrigation system can offer monitoring and prediction based on the specific crops, soil topology and prevailing weather conditions. It can very instrumental in irrigation scheduling based on the yield forecasting for the highly sensitive crops [30]. The net result will be a highly optimal yield in farming operations.

\section{G. Smart Farm Warehouse}

A smart warehouse can help a farm implement an efficient, tracking and management center. Through IoT sensors, automatic timely reordering of farm supplies and machinery spare parts can be done which ensures continuous farm operations with reduced farm breakdowns, minimal time wastage as well as reduced farm inventory costs. Also, RFID (radio frequency identification) sensors can be used to distinctly tag the farm yield and therefore, enable secure and precise traceability of farm harvest throughout the supply chain i.e., from the farm field to the store in the warehouse then to the vendors who distribute it to the consumers. Further, by automatically monitoring the storage conditions of the farm yields, optimal conditions can be set by the IoT based storage system in order to reduce the post-harvest losses, improve yields and increase farm productivity.

Therefore, this technological implementation of the smart warehouse in the farm can ensure that there is (1) farming evaluative metrics where scores and indices can be provided for the farmer and consumer based on the value-driven operations, (2) goal-setting market feedback based on the farm processes and/or products, and (3) blockchain sustainability based on RFID by providing food tracking right from the farm harvesting and storage up to the supply and distribution to the consumers.

\section{IMPACT OF TECHNOLOGY ON AGRICULTURE}

Precision farming - through the implementation of digital farming, real-time and accurate data can be collected from the field leading to the development of a data-driven farming. This data can be employed in the identification of soil and crop requirements for improved productivity, progress monitoring, yield forecasting and optimal natural resources utilization in order to achieve environmental sustainability. Ultimately, the implementation of precision agriculture can contribute to reduced resource wastage and increased farm profit margins.

Farming productivity - the modern automated farming methods contributes largely towards agricultural mechanization as well fulfilling the operational needs of the farm. As much as these technological innovations are highly reliable, in cases of breakdown of farm machinery or failure of technological farm systems, production is halted. But these breakdowns or failures are intermittent and third-party service providers can provide remote troubleshooting, maintenance, and repair. Also, a farmer may be advised to keep a widespread inventory of machinery spare parts in order to minimize the machinery downtime and ensure that there is a continuous operation even after a breakdown is experienced. The net result of implementing the technological farming systems is that there is an increased farm outputs and hence a higher productivity.

Knowledge gap - there is possibility that it can be challenging to the farmers to adapt to the digital farming technology, interpret the computerized results and may also present operational difficulties due to the various technical systems that are integrated. This may demand that the farmer invests in a practical training and demonstrations on how to operate the farm machinery, and even learning basic computing concepts in order to effectively operate, implement and utilize the farming systems. Sometimes these trainings can be time-consuming, challenging, strenuous or even inadequate.

Employment opportunities - there is the drawback that the implementation of the emerging farming technologies will adversely render farm workers jobless. By the fact that these farming systems are almost entirely autonomous, it means that there is less human labor that will be required. Therefore, a balance between the extent to which to implement the mechanized farming systems and the need to achieve food security which is under threat [31] can be sought.

Land use - use of highly mechanized, faster, and extensive farm automation technology and machinery can lead to more land that has been put to useful and productive farming. With more land under crop cultivation and reduced human labor needs due to implementation of farm machinery, there will be increased farm yields which in turn will offer higher returns on farming to farmers and food sustainability to the Kenyan economy.

Mobile Applications - with the latest smartphone technology, farmers can now integrate the farm automation technologies for easier and convenient remote monitoring on their smartphones and tablets.

\section{CONCLUSION}

Modern agriculture that integrates smart technological mechanization is growing at a very fast rate. In Kenya, like other developing African countries, adoption of these farm automation can result into improved quality and precision farming which in turn will improve on agricultural productivity and in overall, efficiency on the value-chain in farming. The incorporation of these modern mechatronic and automation systems that include the integration of drone farming, smart poultry, smart dairy, smart greenhouse, smart irrigation, and smart warehouse can be a game changer in the current challenge of food sustainability. The major challenge of knowledge gap can be addressed by the Kenyan government through formulation of sustainable agricultural policies that can increase the access to knowledge resources as well as funding opportunities. Future research on this subject will help bring into focus the qualitative aspect of the impact of the integration of these farm automation technologies in realizing food security in Kenya as well as other developing countries. 


\section{CONFLICT OF INTEREST}

The authors declare that they do not have any conflict of interest.

\section{REFERENCES}

[1] Ericksen PJ, Ingram JSI, Liverman DM. Food security and global environmental change: emerging challenges. Environmental Science \& Policy, 2009 Jun;12(4):373-377.

[2] The future of food and agriculture. Alternative pathways to $2050 \mid$ Policy Support and Governance| Food and Agriculture Organization of the United Nations. [Accessed 2021 May 14].

[3] ACTED. 2020 Global Hunger Index: A year of crisis slows progress towards hunger eradication. 2020 [Accessed 2021 May 24].

[4] GFSI. Global Food Security. [Accessed 2021 May 24].

[5] Shamshiri R, Kalantari F, Ting K, Thorp K, Hameed I, Weltzien C, et al. Advances in greenhouse automation and controlled environment agriculture: A transition to plant factories and urban agriculture. International Journal of Agricultural and Biological Engineering, 2018 Jan 31;11.

[6] Big4. The Big 4 - Empowering the Nation [Internet]. Available from https://big4.delivery.go.ke/ [Accessed 2021 May 24].

[7] Government of Kenya. Monitoring. And planning in Kenya. https://monitoring.planning.go.ke/wp-content/uploads/2020/10/BigFour-Agenda-Report-2018_19.pdf [Accessed 2021 May 24].

[8] Xie L, Luo B, Zhong W. How Are Smallholder Farmers Involved in Digital Agriculture in Developing Countries: A Case Study from China. Land. 2021 Mar;10(3):245. [Accessed 13 ${ }^{\text {th }}$ May 2021].

[9] Pesce M, Kirova M, Soma K, Bogaardt MJ, Poppe K, Thurston C, et al. Research for AGRI Committee-Impacts of the digital economy on the food-chain and the CAP. European Parliament, Policy Department for Structural and Cohesion Policies: Brussels, Belgium. 2019. https://www.europarl.europa.eu/thinktank/en/document/IPOL_STU(2 019) 629192 [Accessed 28th May 2021].

[10] Oliverwyman. Agriculture 4.0 - The Future Of Farming Technology https://www.oliverwyman.com/ourexpertise/insights/2018/feb/agriculture-4-0--the-future-of-farmingtechnology.html [Accessed 2021 May 27].

[11] Jha K, Doshi A, Patel P, Shah M. A comprehensive review on automation in agriculture using artificial intelligence. Artificial Intelligence in Agriculture, 2019 Jun.

[12] Shockley J, Dillon C, Shearer S. An economic feasibility assessment of autonomous field machinery in grain crop production. Precision Agriculture, 2019.

[13] Islam MM, Sourov Tonmoy S, Quayum S, Sarker AR, Umme Hani S, Mannan MA. Smart Poultry Farm Incorporating GSM and IoT. In: 2019 International Conference on Robotics,Electrical and Signal Processing Techniques (ICREST). 2019. p. 277-80.

[14] EOS. Precision Agriculture: How To Improve Farming With Satellite Data 2019. https://eos.com/blog/precision-agriculture-from-conceptto-practice/ [Accessed 2021 May 27]

[15] Lunner-Kolstrup C, Hörndahl T, Karttunen JP. Farm operators' experiences of advanced technology and automation in Swedish agriculture: a pilot study. Journal of Agromedicine, $2018 \mathrm{Jul}$ 3;23(3):215-26.

[16] Ünal İ, Topakci M. Design of a Remote-Controlled and GPS-Guided Autonomous Robot for Precision Farming. International Journal of Advanced Robotic Systems, 2015 December.

[17] Pedersen SM, Fountas S, Have H, Blackmore BS. Agricultural robots - system analysis and economic feasibility. Precision Agric, 2006 Sep 1; 7(4):295-308.

[18] Moorehead S, Wellington C, Gilmore B, Vallespi C. Automating Orchards: A System of Autonomous Tractors for Orchard Maintenance. 2012.

[19] Zhang Z, Noguchi N, Ishii K, Yang L, Zhang C. Development of a Robot Combine Harvester for Wheat and Paddy Harvesting. IFAC Proceedings Volumes, 2013 Jan 1;46(4):45-48.

[20] Yamaha. Precision Agriculture - RMAX [Internet]. Available from: https://www.yamahamotorsports.com/motorsports/pages/precisionagriculture-rmax. [Accessed 2021 May 26]

[21] SMARTBOW. Herd Monitoring Software | SMARTBOW https://www.smartbow.com/en/home.aspx [Accessed 2021 May 26].

[22] Schweinzer V, Gusterer E, Kanz P, Krieger S, Suess D, Lidauer L, et al. Evaluation of an ear-attached accelerometer for detecting estrus events in indoor housed dairy cows. Theriogenology, 2019 Mar 1;130.
[23] Choukidar GA, Dawande NA. Smart Poultry Farm Automation and Monitoring System. In: 2017 International Conference on Computing Communication, Control and Automation (ICCUBEA), 2017. p. 1-5.

[24] Jilani MT. Comparative Analysis of Wireless Technologies for Internet-Of-Things Based Smart Farm. Science International. 2017 Jan 1;29:373-8.

[25] Hamdi S, Ahmed A, Bilal G. Smart Greenhouse Powered by Solar Energy: A Review. Solid State Technology, 2021 May 10;64:4280-93.

[26] Wangmo P, Jadoun VK, Agarwal A. A Review on Solar Energy-Based Smart Greenhouse. In: Recent Advances in Mechanical Engineering Select Proceedings of NCAME, 2019:629-634. Springer Gabler.

[27] Kumar H, Jain PK, editors. Recent Advances in Mechanical Engineering. Singapore: Springer; 2020. p. 629-634. (Lecture Notes in Mechanical Engineering).

[28] Vij A, Vijendra S, Jain A, Bajaj S, Bassi A, Sharma A. IoT and Machine Learning Approaches for Automation of Farm Irrigation System. Procedia Computer Science, 2020 Jan $1 ; 167: 1250-1257$.

[29] Azeta J, Bolu CA, Alele F, Daranijo EO, Onyeubani P, Abioye AA. Application of Mechatronics in Agriculture: A review. J Phys: Conf Ser. 2019 December.

[30] Groener B, Knopp N, Korgan K, Perry R, Romero J, Smith K, et al. Preliminary Design of a Low-cost Greenhouse with Open Source Control Systems. Procedia Engineering, 2015 Dec;107:470-479.

[31] Roopaei M, Rad P, Choo K-KR. Cloud of Things in Smart Agriculture: Intelligent Irrigation Monitoring by Thermal Imaging. IEEE Cloud Computing, 2017 Jan 1;4:10-15.

[32] ISSAfrica.org. Food security under threat in Kenya [Internet]. ISS Africa. 2018. Available from: https://issafrica.org/iss-today/foodsecurity-under-threat-in-kenya [accessed 2021 May 27]. 